\title{
The Prevalence and Clinical Characteristics of the Healthcare Workers Infected with SARS Cov-2 in Baqubah Teaching Hospital, Diyala-Iraq
}

Imad A Lateef (MD, CABM) ${ }^{1}$, Mohamed A Al-Karkhi $(\mathrm{PhD})^{2}$, Zainab M Atta $(\mathrm{BSc}, \text { Nursing })^{3}$, Arshed A Ahmad $(\mathrm{PhD})^{4}$

${ }^{1}$ Baqubah teaching hospital, Diyala health directorate, Diyala, Iraq

${ }^{2}$ Baqubah teaching hospital, Diyala health directorate , Diyala, Iraq

${ }^{3}$ Baqubah teaching hospital, Diyala health directorate, Diyala, Iraq

${ }^{4}$ Computer department, College of Education for pure sciences, University of Diyala, Diyala, Iraq

Correspondence Address:

Dr. Imad A Lateef

Baqubah teaching hospital, Diyala health directorate, Diyala, Iraq

email: emadahmed_aldulaimi@yahoo.com

Received: 9 November 2020

Revised: 17 November 2020

Accepted: 29 November 2020

Published: 25 June 2021

Diyala Medical Journal 2021:20(2): 14- 22

\section{Abstract}

Background: In 2019, a novel coronavirus was identified. It first appeared in Wuhan, China and caused a cluster of pneumonia cases. The virus was named severe acute respiratory syndrome coronavirus-2 (SARS-CoV-2). The World Health Organization designated the disease COVID-19 (coronavirus disease 2019).

Objective: To find the prevalence of COVID-19 infection among symptomatic frontline and non-frontline healthcare workers, their main complaint and clinical outcomes.

Patients and Methods: This is a cross sectional study done on retrospective data in which all symptomatic healthcare workers in Baqubah teaching hospital were involved in the study and full questionnaire forms were filled. Nasal and throat swabs were taken for polymerase chain reaction test and high-resolution computed tomography were done.

Results: From (1413) symptomatic healthcare workers tested for COVID-19 (185) were positive yielding a (13\%) prevalence from the total employed healthcare workers in Baqubah teaching hospital, with (63\%) were male. Most of the affected were nurses $(63.2 \%),(59.5 \%)$ of the affected healthcare workers were non-frontline staff. Fever was the most common symptom and was seen in $(79.5 \%)$ followed by shortness of breath in $(63.8 \%)$. The disease course was mild in $(83.8 \%)$ of the affected healthcare workers and only $(2.7 \%)$ need admission to the hospital and the mortality rate was $(0.5 \%)$. 
Conclusion: Most infections among healthcare workers occurred during the last two months of the disease outbreak. The prevalence of the COVID-19 infection among our healthcare workers was high and mostly in non-frontlie staff. Rapid identification of staff with potential infection and routine screening among asymptomatic staff could help protect other healthcare workers.

Keywords: COVID-19; Healthcare workers; Baqubah teaching hospital

\section{Introduction}

In 2019, a novel coronavirus was identified. It first appeared in Wuhan, China and caused a cluster of pneumonia cases. The virus was named severe acute respiratory syndrome coronavirus-2 (SARS-CoV-2). The World Health Organization designated the disease COVID-19 (coronavirus disease 2019) [1]. Then it was declared a pandemic by the World Health Organization on March 11, 2020. It continues to disrupt life for millions around the globe [2].

An Iraqi family of four who returned from Iran tested positive for the coronavirus in Kirkuk governorate. They were the first Iraqis known to have caught the disease, a day after an Iranian student in the Najaf governorate became Iraq's first confirmed case on February 24 ${ }^{\text {th }}, 2020$ [3]. Subsequently, the number of confirmed cases were increased all over the country with over $(100,000)$ confirmed cases and $(4,000)$ deaths countrywide as of July $25^{\text {th }}, 2020$ [4].

In the fight against COVID-19, Healthcare workers are the most important human resource for hospitals [5]. Healthcare workers (HCWs) potentially experience greater risks for emerging infectious diseases [6-8] due to occupational exposure to sick patients and virus-contaminated surfaces [9]. Contagious HCWs may infect patients, co-workers and family members. Moreover, the removal of ill (HCWs) from duty can threaten essential healthcare staffing during an epidemic [10].

Therefore, infection prevention and quick, accurate diagnosis of potential COVID-19 in (HCWs) are crucial to maintaining hospital operations [11].

Testing of staff at our institution may also have provided a limited snapshot of the SARS-CoV-2 prevalence in the community (i.e. those are not requiring hospital admission) with mild influenza-like illness or persistent cough.

The aim of this study is to find the prevalence of COVID-19 infection among symptomatic frontline and non-frontline healthcare workers, their main complaint and clinical outcomes.

\section{Patients and Methods}

This is a cross-sectional study done on retrospective data in which all symptomatic healthcare workers in Baqubah teaching hospital were involved in the study and full questionnaire form was filled including the patient demographic data, clinical features, PCR result, CT result, treatment ,outcome, and history of contact with COVID-19 patients. The period was from May $20^{\text {th }} 2020$ to July $31^{\text {st }} 2020$ which is the period where the number of cases increased both in the hospital and the community. 
The policy in our hospital is all symptomatic healthcare workers with respiratory complaints, gastrointestinal complaints or fever are seen by physicians and full investigations are done, including nasal and throat swabs for Polymerase Chain Reaction (PCR) test. The patient kept isolated at home pending the investigation result come. All confirmed cases were given (1421) day sick leave and according to the severity of the disease.

Procedure :Health workers at the laboratory were trained for performing nasal and throat swabs, which include insertion of flexible synthetic nasal fiber into one nostril for 2-3 seconds with rotation for 360 degrees for 10 15 seconds ,the same procedure were done on the other nostril, also wooden stick was applied for throat swab with same procedure used for nasal swab ,both swabs were placed for each viral transport media ,all samples were sent to Diyala -public health laboratory within 1 hour and refrigerated until to be tested later by PCR.

\section{Investigation of samples}

All swab samples were tested at Diyala public health laboratory - molecular biology unit with two steps; automated extraction (Dane gene extraction kits) which done by automated extraction device (smart32) and real-time PCR methods (sacace BIOTECHNOLOGIES kits) by analytical
PCR device .The time for results ranged from 6-8 hours, all results were interpreted as positive and negative and send to the hospital.

For those with typical signs and symptoms who had negative (PCR) chest computed tomography was done using Toshiba device.

\section{Statistical analysis}

Given the descriptive nature of this study analysis for statistical significance was not performed. Continuous variables were expressed as medians. Categorical variables were summarized as counts and percentages. There were no missing data. All analyses were performed with SPSS statistical software version 25.0.

\section{Results}

A total of (1413) symptomatic healthcare workers were tested for COVID-19 from May $20^{\text {th }} 2020$ to July $31^{\text {st }}, 2020$. From them (185) staff members were tested positive for COVID-19, yielding an overall prevalence of (13\%) from the total number of healthcare workers in the hospital. From them 117 (63\%) were male with median age (28).

PCR positive were found in (175) $(94.6 \%)$ of them, while others 10 (5.4\%) were PCR negative, but they had typical signs and symptoms with typical computed tomography (CT) chest findings. Most of affected healthcare workers were nurses 117(63.2\%) Table 
The Prevalence and Clinical Characteristics of The Healthcare Workers Infected with Sars Cov-2 in Baquba Teaching Hospital, Diyala-Iraq

Table (1): Demographic characteristics of patients

\begin{tabular}{|c|c|c|c|c|c|c|}
\hline & \multicolumn{2}{|c|}{$\begin{array}{c}\begin{array}{c}\text { Positive PCR } \\
n=175\end{array} \\
\text { n }\end{array}$} & \multicolumn{2}{|c|}{$\begin{array}{c}\begin{array}{c}\text { Negative PCR } \\
n=10\end{array} \\
\end{array}$} & \multicolumn{2}{|c|}{ Total $n=185$} \\
\hline & $\mathrm{n}$ & $\mathrm{n}$ & $\mathrm{n}$ & $\%$ & $\mathrm{n}$ & $\%$ \\
\hline \multicolumn{7}{|c|}{$\overline{\text { Sex }}$} \\
\hline Male & 113 & 1117 & 4 & 40 & 1117 & 63.2 \\
\hline Female & 62 & 68 & 6 & 60 & 68 & 36.8 \\
\hline \multicolumn{7}{|c|}{ Age group (years) } \\
\hline $20-30$ & 118 & 123 & 5 & 50 & 123 & 66.5 \\
\hline $31-40$ & 36 & 38 & 2 & 20 & 38 & 20.5 \\
\hline $41-50$ & 14 & 16 & 2 & 20 & 16 & $\overline{8.6}$ \\
\hline $51-60$ & 7 & 8 & 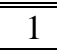 & 10 & 8 & 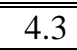 \\
\hline \multicolumn{7}{|c|}{ Medical profession } \\
\hline Medical doctor & 29 & 34 & $\overline{5}$ & 250 & 34 & 18.4 \\
\hline Nurse & 113 & 117 & $\overline{44}$ & 40 & 117 & 63.2 \\
\hline Other healthcare worker & 33 & 34 & 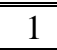 & 10 & 34 & 18.4 \\
\hline
\end{tabular}

In this study the most affected healthcare wards and had no direct contact with SARS workers $110(59.5 \%)$ work in non-frontline COVI-19 positive cases, Table (2).

Table (2): Distribution of the affected healthcare workers according to their workplaces

\begin{tabular}{|c|c|c|c|c|c|c|}
\hline & \multicolumn{2}{|c|}{ Positive PCR } & \multicolumn{2}{|c|}{ Negative PCR } & \multicolumn{2}{|c|}{ Total } \\
\hline & $\mathrm{n}$ & $\%$ & $\mathrm{n}$ & $\%$ & $\mathrm{n}$ & $\%$ \\
\hline \multicolumn{7}{|c|}{ Frontline } \\
\hline Male & 53 & 76.8 & 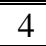 & 66.7 & 57 & 76 \\
\hline Female & 16 & 23.2 & 2 & 33.3 & 18 & 24 \\
\hline \multicolumn{7}{|c|}{ Non-Frontline } \\
\hline Male & 57 & 53.8 & 3 & 75 & 60 & 54.5 \\
\hline Female & 49 & 46.2 & 1 & 25 & 50 & 45.5 \\
\hline Total & 175 & 100 & 10 & 100 & 185 & 100 \\
\hline
\end{tabular}

The most common complaint was fever in $147(79.5 \%)$ of affected healthcare workers and shortness of breath in $118(63.8 \%)$ of them, while $11(5.9 \%)$ were asymptomatic.
Medical comorbidities like cardiac, pulmonary, immune diseases and tumors were found only in 23 (12.4\%) Table (3). 
The Prevalence and Clinical Characteristics of The Healthcare Workers Infected with Sars Cov-2 in Baquba Teaching Hospital, Diyala-Iraq

Table (3): The main symptoms of affected healthcare workers and comorbidities

\begin{tabular}{|l||c||}
\hline \multicolumn{1}{|c||}{ Symptoms (n=185) } & No. (\%) \\
\hline \hline Fever & $147(79.5)$ \\
\hline \hline Muscle aches & $87(47)$ \\
\hline Difficulty breathing & $118(63.8)$ \\
\hline \hline Fatigue & $113(61)$ \\
\hline \hline Anosmia & $101(54.6)$ \\
\hline \hline Cough & $31(16.8)$ \\
\hline \hline Loss of taste & $99(53.5)$ \\
\hline \hline Headache & $66(35.7)$ \\
\hline \hline Sore throat & $47(25)$ \\
\hline \hline GIT symptoms Comorbidities (one or more) \\
\hline \hline No symptoms & $30(16)$ \\
\hline \hline & $4(2.9)$ \\
\hline \hline Chronic lung disease & $7(3.8)$ \\
\hline \hline Tumors and immune system disease & $8(4.3)$ \\
\hline \hline Diabetes mellitus & $7(3.8)$ \\
\hline \hline Hypertension & \\
\hline
\end{tabular}

In this study most of the affected healthcare course, while only 8 (4.3\%) develop severe workers $155(83.8 \%)$ develop mild disease disease Table (4).

Table (4): Distribution of cases according to the disease severity

\begin{tabular}{|c|c|c|c|c|c|c|}
\hline \multirow[t]{2}{*}{ MILD } & \multicolumn{2}{|c|}{ Positive $n=149$} & \multicolumn{2}{|c|}{ Negative $n=6$} & \multicolumn{2}{|c|}{ Total $n=155$} \\
\hline & $\mathbf{n}$ & $\%$ & $\mathbf{n}$ & & $\mathbf{n}$ & $\%$ \\
\hline Male & 95 & 63.8 & 4 & Male & 95 & 63.8 \\
\hline Female & 54 & 36.2 & 2 & Female & 54 & 36.2 \\
\hline \multirow[t]{2}{*}{ MODERATE } & \multicolumn{2}{|c|}{ Positive $n=20$} & \multicolumn{2}{|c|}{ Negative $n=2$} & \multicolumn{2}{|c|}{ Total $\mathrm{n}=22$} \\
\hline & $\bar{n}$ & $\%$ & $\bar{n}$ & $\%$ & $\bar{n}$ & $\%$ \\
\hline Male & 12 & 60 & 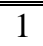 & 50 & 13 & 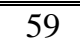 \\
\hline Female & 8 & 40 & 1 & 50 & 9 & 41 \\
\hline \multirow[t]{2}{*}{ SEVER } & \multicolumn{2}{|c|}{ Positive $n=6$} & \multicolumn{2}{|c|}{ Negative $n=2$} & \multicolumn{2}{|c|}{ Total $n=8$} \\
\hline & $\mathbf{n}$ & $\%$ & $\mathbf{n}$ & & $\mathbf{n}$ & $\%$ \\
\hline Male & 2 & 33.3 & 2 & Male & 2 & 33.3 \\
\hline Female & 4 & 66.7 & 0 & Female & 4 & 66.7 \\
\hline
\end{tabular}

Only $5(3 \%)$ healthcare workers need hospital admission in the COVID-19 words due to severe signs and symptoms with bilateral more than $50 \%$ involvement of the lungs with low oxygen saturation on pulse oxymetry Figure (1). 
Figure (1): The percentage of cases who required hospitalization

About the outcome only one dead healthcare mortality rate Figure (2). worker which constitutes $(0.5 \%)$

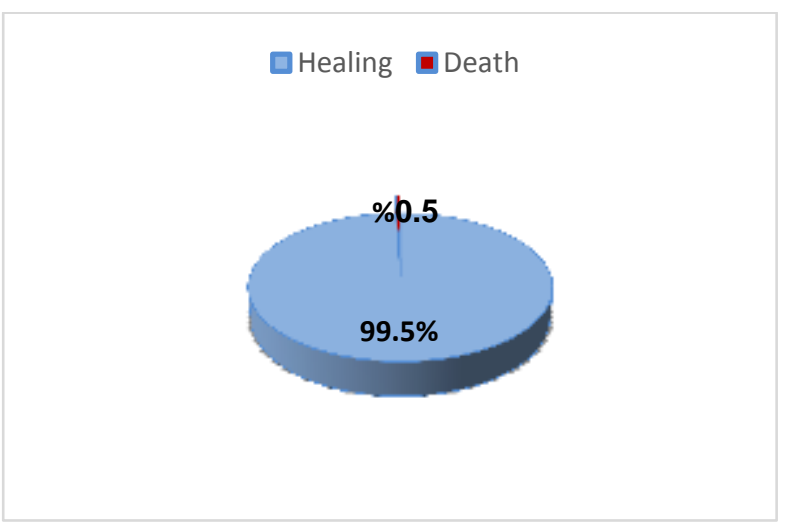

Figure (2): The mortality rate among healthcare workers

The distribution of the affected healthcare in Figure (3). workers during the study period was shown

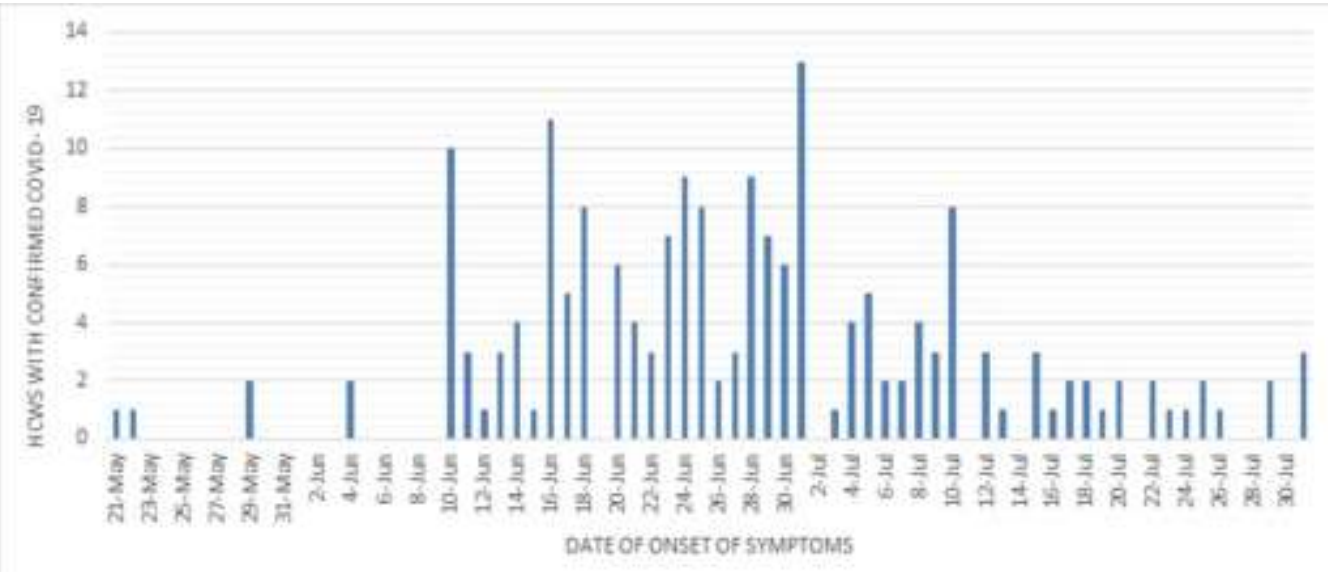

Figure (3): Date of onset of symptoms for the healthcare workers with confirmed COVID-19 


\section{Discussion}

In this study, the prevalence of the affected healthcare workers in Baqubah teaching hospital was (13\%) and this was higher than what found in a study from the USA in 2020 [12] in which the prevalence was (5.3\%), And also higher than the prevalence found by a study done in Germany in 2020 [13] which found $(1 \%)$ prevalence. Also, it's higher than what is found in a study from Wuhan, China in 2020 [14] in which the prevalence was $(1.1 \%)$. But it's lower than the prevalence found in a study from the United Kingdom in 2020 [15] in which the prevalence was $(18 \%)$. And this difference may be due to the difference in the sample size and time of collection of the sample.

Most of the affected healthcare workers in our study were nurses (63.2\%) and this agrees with the study from Wuhan, China in 2020 [14] in which the nurses affected $(54.6 \%)$ but it's higher than what found in studies from the United Kingdom [15] and Germany [13] in 2020 which show that nurses form (48\% and $28 \%)$ respectively.

In this study, most of the affected healthcare workers $(59.5 \%)$ work in nonfrontline wards and this agrees with the study from Wuhan, China in 2020 [14]in which the non-frontline workers compose $(84.5 \%)$. But it disagrees with the study from USA in 2020 [12] in which the non-frontline workers compose only $(33.5 \%)$ of the affected healthcare workers. And another study from the USA in 2020 [16] shows that $(77.1 \%)$ of the affected healthcare workers were from frontline staff.

Fever was the most common complaint and seen in $(79.5 \%)$ of the cases followed by shortness of breath in $(63.8 \%)$ of them. And this agrees with the study from Wuhan, China in 2020 [14] in which fever was the most frequent complaint, and seen in (60.9\%). While other studies from the USA $[12,16]$ and Germany [13] showed that fever was not the most common complaint and seen in only $(38.4 \%, 41.7 \%$ and $53 \%$, respectively).

Medical comorbidities like cardiac, pulmonary, immune diseases and tumors were found only in (12.4\%) and this was comparable to the percentage seen in the studies from the USA [12] and Wuhan, China [14] in which the percentage of the healthcare workers who had chronic medical illnesses were see (12.4\% and $12.7 \%$, respectively) but it is lower than that found by another study from the USA [16] which found that (47.9\%) of the healthcare workers had chronic medical illnesses.

Most of the affected healthcare workers in this study had a mild disease course and this agrees with the study from the Germany [13] which revealed that most healthcare workers with COVID-19 experienced mild disease. And the other study from Wuhan, China in 2020 [14] which revealed that $(84.5 \%)$ of the affected healthcare workers with COVID-19 had non severe disease.

Also $(2.7 \%)$ of the affected healthcare workers were required hospitalization in this study. And it is comparable to the finding in the studies from the USA [12] and Germany [13] which revealed a hospitalization rate of (3.2\% and $2 \%$, respectively). But it is higher than the rate found by the study from the United Kingdom in 2020 [15] which state that none of the staff who tested positive for SARS-CoV-2 required hospital admission at the time of their positive result. And it is 
lower than the rate found by another the USA study in 2020 [16] which revealed that hospitalization rate was $(6.3 \%)$.

About the mortality rate in our study it was $(0.5 \%)$, which is lower than that found in the study from Wuhan, China in 2020 [14] which showed a mortality rate of $(0.9 \%)$. But it is higher than the other studies from the USA [12,16], Germany [13] and United Kingdom [15] in 2020 when all of them showed a that mortality rate was zero.

\section{Conclusions}

Most infections among healthcare workers occurred during the last two months of the disease outbreak and it is the time of increase in the infection rates all-over the country. That the prevalence of the COVID-19 infection among our healthcare workers was high and mostly in non-frontt-line staff so full personal protective measures were needed with good personal hygiene. Rapid identification of staff with potential infection and routine screening among asymptomatic staff could help protect other healthcare workers.

\section{Recommendations}

1-That good personal hygiene and wearing personal protective equipment(PPE) were very important for all healthcare workers not only for frontline one.

2-Contineous full training courses on who to use(PPE) were needed.

3-Another study needed to follow those infected staff for any future complications.

4-Increasing laboratory capacity to allow widespread testing of the staff could be a vital tool in achieving adequate staffing during the COVID-19 outbreak, and reducing the risk of transmission to vulnerable patients.

\section{Source of funding: Nill}

Ethical clearance: This study was granted ethical approval from the Ethical Committee of the Collage of Medicine at Diyala medical University.

Conflict of interest: The author declares that there is no conflict of interest regarding the publication of this article.

\section{References}

[1]Zhu N, Zhang D, Wang W, Li X, Yang B, Song J, Zhao X, Huang B, Shi W, Lu R, Niu P. A novel coronavirus from patients with pneumonia in China, 2019. N. Engl. J. Med. 2020 .

[2]World Health Organization. WHO Director-General's opening remarks at the media briefing on COVID-19. 2020. https://www.who.int/dg/speeches/detail/whodirector-general-s-opening-remarks-at-themedia-briefing-on-covid-19.

[3]Al-Malkey MK, Al-Sammak MA. Incidence of the COVID-19 in IraqImplications for travellers. Travel Med Infect Dis. 2020.

[4]World Health Organization. Coronavirus disease (COVID-2019) situation reports.Available:https://www.who.int/emerg encies/diseases/novel.coronavirus2019/situati on-reports. 2020.

[5]Cheng VC, Wong SC, Yuen KY. Estimating coronavirus disease 2019 infection risk in health care workers. JAMA Network Open. 2020;3(5): e209687.

[6]Lan FY, Wei CF, Hsu YT, Christiani DC, Kales SN. Work-related COVID-19 transmission in six Asian countries/areas: A 
The Prevalence and Clinical Characteristics of The Healthcare Workers Infected with Sars Cov-2 in Baquba Teaching Hospital, Diyala-Iraq

follow-up study. PloS one. 2020;15(5):e0233588.

[7]Selvaraj SA, Lee KE, Harrell M, Ivanov I, Allegranzi B. Infection rates and risk factors for infection among health workers during Ebola and Marburg virus outbreaks: a systematic review. The Journal of infectious diseases. 2018;218(suppl_5): S679-89.

[8]Offeddu V, Yung CF, Low MS, Tam CC. Effectiveness of masks and respirators against respiratory infections in healthcare workers: a systematic review and metaanalysis. Clin. Infect. Dis. 2017;65(11):1934-42.

[9]Reusken CB, Buiting A, Bleeker-Rovers C, Diederen B, Hooiveld M, Friesema I, Koopmans M, Kortbeek T, Lutgens SP, Meijer A, Murk JL. Rapid assessment of regional SARS-CoV-2 community transmission through a convenience sample of healthcare workers, the Netherlands, 2020. Eurosurveillance. 2020;25(12):2000334.

[10]Fraher EP, Pittman P, Frogner BK, Spetz J, Moore J, Beck AJ, Armstrong D, Buerhaus PI. Ensuring and sustaining a pandemic workforce. N. Engl. J. Med. 2020;382(23):2181-3.

[11]Lan FY, Fernandez-Montero A, Kales SN. COVID-19 and healthcare workers: emerging patterns in Pamplona, Asia and Boston. Occupational Medicine. 2020.

[12]Mani NS, Budak JZ, Lan KF, BrysonCahn C, Zelikoff A, Barker GE, Grant CW, Hart K, Barbee CJ, Sandoval MD, Dostal CL. Prevalence of COVID-19 infection and outcomes among symptomatic healthcare workers in Seattle, Washington. Clin. Infect. Dis. 2020.

[13]Kluytmans-van den Bergh MF, Buiting $A G$, Pas SD, Bentvelsen RG, van den
Bijllaardt W, van Oudheusden AJ, van Rijen MM, Verweij JJ, Koopmans MP, Kluytmans JA. Prevalence and clinical presentation of health care workers with symptoms of coronavirus disease 2019 in 2 Dutch hospitals during an early phase of the pandemic. JAMA network open. 2020;3(5): e209673.

[14]Lai X, Wang M, Qin C, Tan L, Ran L, Chen D, Zhang H, Shang K, Xia C, Wang S, $\mathrm{Xu}$ S. Coronavirus disease 2019 (COVID2019) infection among health care workers and implications for prevention measures in a tertiary hospital in Wuhan, China. JAMA Network Open. 2020;3(5): e209666-e209666. [15]Keeley AJ, Evans C, Colton H, Ankcorn M, Cope A, Bennett T, Giri P, de Silva TI, Raza M. Roll-out of SARS-CoV-2 testing for healthcare workers at a large NHS foundation trust in the United Kingdom, March 2020. Eurosurveillance. 2020;25(14):2000433. [16]Chow EJ, Schwartz NG, Tobolowsky FA, Zacks RL, Huntington-Frazier M, Reddy SC, Rao AK. Symptom screening at illness onset of health care personnel with SARSCoV-2 infection in King County, Washington. JAMA. 2020;323(20):20872089. 